\title{
An Evaluation of EFL Teachers' Perceptions of Blended Learning
}

\author{
Deana Ismayana ${ }^{1}$, Herri Mulyono ${ }^{2}$, Gunawan Suryoputro ${ }^{3}$,Cahya Komara ${ }^{4}$ \\ \{deana.ismayana@gmail.com\}
}

University of Muhammadiyah Prof. Dr. Hamka, Jakarta, Indonesia

\begin{abstract}
This paper report on a preliminary study of English as a foreing language (EFL) teachers' perception of blended learning practices. In the study, a total of $247 \mathrm{EFL}$ teachers across education levels were surveyed. Findings of the study revealed that teachers' perceptions on their skill and experience $(\mathrm{F}=1.640$, Sig. $=0.201)$ and motivation $(\mathrm{F}=0.002$, Sig. $=0.969)$ of blended learning was not predisposed by their gender. Their perceptions of interaction and communication $(F=1.483$, Sig. $=0.224)$ to use blended learning also was not affected by gender. The gender also does not affect their perceptions toward the effectiveness and flexibility indicator $(\mathrm{F}=0.966$, Sig. $=$ 0.327 ) that blended learning offers.
\end{abstract}

Keywords: blended learning, EFL teacher

\section{Introduction}

The information and communication technology (ICT) advancement nowadays has been resulted in the prompt growth of many aspects of life. It also has led the educational institution to recognize the span-new prospect to increase the quality of education (Al-Qahtani \& Higgins, 2013). Different approach to teaching that integrating technology also has been growing. One of the popular approaches is online learning. However, online learning cannot replace face-to-face interaction [2] that resulted in the new learning approach called blended learning [3]. Blended learning is a combination of two-settings learning, a face to face traditional learning and online learning [4].

Bidder, Mogindol, \& Saibin (2016) defined blended learning as the affiliation of face-toface learning with synchronous and/or asynchronous online learning. On the other hand, blended learning, which also popular as hybrid learning, is referred to the integration of online learning into the traditional learning where the stakeholders may choose the right composition of teaching modalities, teaching media, teaching method, and internet-technology use to meet specific goals of teaching and learning [2], [6], [7]. In the current study, blended learning is defined as simply the combination of face-to-face and online learning that can be adjusted according to the instructional teaching goals.

Blended learning has plenty of advantages to offer. As the term of blended learning, it blends both the advantages of traditional and online learning [2], [8], [9]. It facilitates both the students and the instructors to get into a new atmosphere of learning where they got twofold benefits at once, both face to face learning and online learning. Blended learning also allows the students to learn at their rate. Besides, students still have regular time in class consistently. 
The instructors are also entitled to reinforce traditional classroom material through online learning [8]. It also provides the teachers and the students a place to connect, interact, and communicate outside classroom that may sustain their learning community [10]. Furthermore, it reduces the course cost and reduces the dropout number, too [9].

When implementing blended learning, there are several challenges to deal with also .The implementation of blended learning entails detail instructional design of both face-to-face and online programs. The teacher requires extra time for managing the course plan, providing suitable material, an d developing course activity for the appropriate meeting. Lack of training and support also take part in the challenges of blended learning implementation. The teacher often assumes that the learning management system (LMS) is complicated to use because of insufficient training and support [8]. Having the materials online sometimes also affecting face-to-face classroom quality. Students tend to download the content without even read it at home [11]. Another challenge is that the students may not have a skillful computer literacy which makes them feel uncomfortable and ignore the online materials [7].

However, several studies also have confirmed the effectiveness of blended learning approach. Zibin (2018) conducted an experimental study on the effect of blended learning toward written discourse. Sixty Jordanians students majoring Engling as a Foreign Language (EFL) study participated in this study. The study revealed that blended learning is useful for writing skills generally and specifically for clause combining acquisition. Yang (2012) examined the effect of blended learning for university students who are dealing with English reading difficulties. One-hundred and eighty-three EFL students in Taiwan that divided into an experimental and control group took part in this study. The findings revealed that blended learning is sufficient to be used for improving students' reading skill with the right implementation of offline and online learning.

Despite all of that, indeed there is a need to understand first what are the practitioners, such as students and teachers, perceptions of the use of blended learning. Many studies have examined students' perceptions of blended learning. Thang, Wong, \& Noor (2012) explored undergraduate Malaysian students' perceptions of blended learning approach in learning EAP (English for Academic Purposes). Nine focus group interviews that consist of 31 students takes part in this study. The result revealed that most of the students, from both high proficiency and low proficiency level, perceived positive perspectives toward the course. Hung \& Chou (2015) investigated students' perceptions of the roles of blended and online learning instructors. About 750 students, in a Taiwan private university, responded to the Online Instructors Role and Behavior Scale (OIRBS) survey. The OIRBS survey contains five sections. The result showed that the students perceived the instructors' role as social supporters as the lowest role

Not only students' perceptions but also teachers' perceptions were investigated. First, Aldosemani and Shepherd's (2018) study investigated the instructors' perception and challenges of the implementation of blended learning. About 124 academic staff of public Saudi Arabia University took part in this research. The findings revealed that Saudi Arabia instructors had positive perceptions of Blended Learning, especially where they got greater flexibility in blended learning, and both of them and their students can access the material anytime. However, the study also revealed that they found several challenges of blended learning, such as lack of training, experience, and skill, and also experiencing technical difficulties while implementing the blended approach. Second, Kuo, Belland, Schroder, \& Walker, (2015) explored the teachers' perceptions and satisfaction towards three interaction types of blended learning, which are learner-learner interaction, learner-instructor interaction and learner-content interaction. Twenty-two teachers who took a distance education master 
program in some university in intermountain participated in this study. Teachers showed positive attitudes of the interaction types in the blended course, especially in learner-content interaction.

As many previous studies that explore the students and teachers' perceptions of blended learning. This study aims to examine EFL teachers' perceptions of blended learning and the challenges that appear during the application of blended learning. As well as students perceptions of blended learning, teachers' perceptions play an important role in the implementation of blended learning. The findings of this present study also may contribute to the references of the related study. This study is aimed to give answers to the following research questions:

1. What are EFL teachers' perceptions of blended learning?

\section{Method}

This research used quantitative approach with a survey as the data collection method. A five-likert scale instrument was distributed to 247 EFL teachers. The questionnaire was developed from [8]'s research consisting of demographic questions and twenty item perceptions of blended learning. The twenty-item questions of perceptions was divided into four factors, namely 1) Skill and experience, 2) Motivation, 3) Interaction and communication, 4) Effectiveness and flexibility (see Table 1). In order to make clear and convenient questions, the instrument was translated to Bahasa Indonesia eventhough the participants were EFL teachers. For analyzing the data after data collecting for about two months, a Rasch Model Measurement (WINSTEP) and SPSS version 24 were used. In examining EFL teachers perceptions, descriptive statistics, and frequencies that include the score, mean score, logit score, and standard deviation were utilized. After describing the perceptions, the one-way analysis of variance (ANOVA) was established to see if there is a significant difference variance of gender and teachers' teaching level. After knowing its significant differences, a posteriori test was conducted using the Tukey test.

\section{Findings And Discussion}

\subsection{Instrument Reliability}

The reliability analysis was performed after gaining the data. The result showed that the instrument had a high Cronbach's alpha score (0.740).

\subsection{EFL Teachers' Perceptions of Blended Learning}

To answer the first research question, descriptive statistics have been conducted. The participants divided into two groups: respondent who has positive and negative perceptions with 60 points as the mid-score of total 100 points (twenty items with five as the highest point). It shows that $79.75 \%$ of participants with mean 69.38 showed positive perspectives towards blended learning and the rest of them were negative (see Table 1). 
Table 1. Descriptive statistics based on perceptions

\begin{tabular}{lllll}
\hline Group & N & Percentage & Mean & SD \\
\hline Positive & 197 & 79.75 & 69.38 & 5.43 \\
Negative & 50 & 20.24 & 55.56 & 5.44 \\
& 247 & 100 & $\mathbf{6 2 . 4 7}$ & \\
\hline
\end{tabular}

Whereas, the total mean score for both groups is 62,47 which indicates positive perceptions for the mid-score 60. It indicated that overall EFL teachers' perceptions were positive towards blended learning. The findings indicated that EFL teachers' perceived positive attitudes towards the implementation of a blended learning approach. Almost $80 \%$ of the respondents showed positive perspectives of blended learning. The result was similar to the previous study [8] in exploring instructors' perceptions of blended learning.

\subsection{EFL Teachers' Perceptions based on Indicators}

As stated before, the items of the questionnaire are categorized into four indicators. Motivation indicator gained the higher logit with (1.05) logit which indicated that EFL teachers perceived more positive perceptions toward this indicator. Surprisingly, the result showed that skill and experience factor has the lowest logit score $(0.97)$ though it can be considered as the important factor of the teachers (see Table 2). As Comas-Quin (2011) stated that teachers are the prominent factor of the learner that design a rule of teaching and learning experience. The successful of the implementation of learning practice design depends on how well the teachers understand, adjust, and integrate them into the learning environment. Teachers who have sufficient skill and experience may implement it better. Additionally, teachers' most crucial role is to organize and design the instructional design so that the students have a clear vision of what they have to do in online and in-class learning. Thus, it will determine the successful of instruction [14].

Table 2. Descriptive statistics based on indicators

\begin{tabular}{lccl}
\hline \multicolumn{1}{c}{ Indicator } & Score & SD & $\begin{array}{l}\text { Mean } \\
\text { Logit }\end{array}$ \\
\hline Skill and Experience & 5432 & 1.01 & 0.16 \\
Motivation & 2666 & 0.79 & 2.35 \\
Interaction and Communication & 3881 & 0.97 & 0.18 \\
Effectiveness and Flexibility & 4466 & 0.92 & 1.26 \\
\hline
\end{tabular}

\subsection{Differences based on Demographics}

The analysis of one-way ANOVA was also conducted to explore the significant differences between EFL teachers' perceptions of blended learning and gender (Table 3). The calculation indicates that there are no significant differences between gender and their perceptions of blended learning. The ANOVA calculation showed that teachers' perceptions on their skill and experience $(\mathrm{F}=1.640$, Sig. $=0.201)$ and motivation $(\mathrm{F}=0.002$, Sig.= 0.969) of blended learning was not predisposed by their gender. Their perceptions of interaction and communication $(\mathrm{F}=1.483$, Sig. $=0.224)$ to use blended learning also was not affected by gender. The gender also does not affect their perceptions toward the effectiveness and 
flexibility indicator $(F=0.966$, Sig. $=0.327)$ that blended learning offers. Since there is no significant difference between them, a posteriori test is not required.

Table 3. Significant differences based on gender

\begin{tabular}{lrrrrr}
\hline \multicolumn{1}{c}{ Gender } & \multicolumn{1}{c}{ Sum of Squares } & Df & Mean Square & F & Sig. \\
\hline Skill and Experience & & & & & \\
Between Groups & 1.640 & 1 & 1.640 & 1.644 & .201 \\
Within Groups & 244.406 & 245 & .998 & & \\
$\begin{array}{l}\text { Total } \\
\text { Motivation }\end{array}$ & 246.046 & 246 & & & \\
Between Groups & & & & & \\
Within Groups & .010 & 1 & .010 & .002 & .969 \\
Total & 1686.519 & 245 & 6.884 & & \\
Interaction and Communication & 1686.530 & 246 & & & \\
Between Groups & 1.942 & 1 & & & \\
Within Groups & 320.830 & 245 & 1.942 & 1.483 & .224 \\
Total & 322.773 & 246 & 1.310 & & \\
Effectiveness and Flexibility & & & & & \\
Between Groups & 1.679 & 1 & & & \\
Within Groups & 425.896 & 245 & 1.679 & .966 & .327 \\
Total & 427.575 & 246 & & & \\
\end{tabular}

\section{Conclusions}

The objective of the current study was to explore English as a foreing language (EFL) teachers' perception of blended learning practices. Findings of the study revealed that teachers' perceptions on their skill and experience $(\mathrm{F}=1.640$, Sig. $=0.201)$ and motivation $(\mathrm{F}=$ 0.002 , Sig. $=0.969)$ of blended learning was not predisposed by their gender. Their perceptions of interaction and communication $(\mathrm{F}=1.483$, Sig.= 0.224) to use blended learning also was not affected by gender. The gender also does not affect their perceptions toward the effectiveness and flexibility indicator $(\mathrm{F}=0.966$, Sig. $=0.327)$ that blended learning offers However, the result of this study cannot be generalized to all of EFL teachers in general though the researcher took different teaching level of teachers. As this study only focuses on teachers' perceptions of blended learning approach, further studies may explore the challenge in integrating blended learning approach. Future study also may investigate teachers' readiness on implementing blended approach.

\section{References}

[1] A. A. Y. Al-Qahtani and S. E. Higginst, "Effects of traditional, blended and e-learning on students ' achievement in higher education," J. Comput. Assist. Learn., vol. 29, pp. 220-234, 2013.

[2] Y.-C. Kuo, B. R. Belland, K. E. E. Schroder, and A. E. Walker, "K-12 teachers ' perceptions of and their satisfaction with interaction type in blended learning environments," Distance Educ., vol. 35, no. 3, pp. 360-380, 2015.

[3] D. Adams, B. Sumintono, A. Mohamed, and N. S. M. Noor, "E-learning readiness among students of diverse backgrounds in a leading malaysian higher education institution," Malaysian J. Learn. Instr., vol. 15, no. 2, pp. 227-256, 2018. 
[4] Ç. gdem S. Çardak and K. Selvi, "Increasing teacher candidates' ways of interaction and levels of learning through action research in a blended course," Comput. Human Behav., vol. 61, pp. 488-506, 2016.

[5] C. Bidder, S. H. Mogindol, and T. C. Saibin, "Students' Perceptions of Blended Learning and Achievement," in Envisioning the Future of Online Learning, 2016, pp. 213-225.

[6] G. Kofar, "A Study of EFL Instructors Perceptions of Blended Learning," Procedia - Soc. Behav. Sci., vol. 232, no. April, pp. 736-744, 2016.

[7] L. P. Bueno Alastuey, "Evaluation of a blended learning language course: students ' perceptions of appropriateness for the development of skills and language areas," Comput. Assist. Lang. Learn., vol. 27, no. 6, pp. 509-527, 2013.

[8] T. Aldosemani and C. E. Shepherd, "Perceptions of instructors teaching in Saudi blended learning environments," TechTrends, pp. 1-12, 2018.

[9] M. V. López-pérez, M. C. Pérez-lópez, and L. Rodríguez-ariza, "Blended learning in higher education : Students 'perceptions and their relation to outcomes," Comput. Educ., vol. 56, no. 3, pp. 818-826, 2011.

[10] Y.-F. Yang, "Blended learning for college students with English reading difficulties," Comput. Assist. Lang. Learn., vol. 25, no. 5, pp. 393-410, 2012.

[11] N. Solihati and H. Mulyono, "A hybrid classroom instruction in Second Language Teacher Education (SLTE): A critical reflection of teacher educators," Int. J. Emerg. Technol. Learn., vol. 12, no. 5, pp. 169-180, 2017.

[12] A. Zibin and A. R. M. Altakhaineh, "The effect of blended learning on the development of clause combining as an aspect of the acquisition of written discourse by Jordanian learners of English as a foreign language," J. Comput. Assist. Learn., pp. 1-12, 2018.

[13] S. M. Thang, F. F. Wong, and N. M. Noor, "Using a blended approach to teach English for academic purposes: Malaysian students ' perceptions of redesigned course materials," Int. $J$. Pedagog. Learn., vol. 7, no. 2, pp. 142-153, 2012.

[14] M. Hung and C. Chou, "Students ' perceptions of instructors ' roles in blended and online learning environments : A comparative study," Comput. Educ., vol. 81, pp. 315-325, 2015.

[15] A. Comas-Quin, "Learning to teach online or learning to become an online teacher: an exploration of teachers' experiences in a blended learning course," ReCALL, vol. 23, no. 03, pp. 218-232, 2011. 